\title{
O Pensamento em Watson: Rompendo com o Legado Metafísico e Buscando uma Referência Materializante
}

\author{
Cláudio Ivan de Oliveira ${ }^{1}$ \\ Universidade Católica de Goiás \\ Anderson Clayton Pires \\ Escola Superior de Teologia em São Leopoldo
}

\begin{abstract}
RESUMO - O trabalho de Watson sobre o pensamento foi tratado inadequadamente por muitos intérpretes, gerando uma lacuna na interpretação histórica visto que Watson exerceu ampla influência sobre a Psicologia. Nosso objetivo é sanar parte deste problema esclarecendo as principais posições de Watson sobre pensamento. Nossa hipótese é que a teoria watsoniana sobre o pensamento como hábito é uma forma de referencialização materializante influenciada pela desmetafisicização do pensamento Ocidental proveniente do Iluminismo. Admitimos que a teoria de Watson reproduziu premissas do erro de categoria cartesiano. Assumimos também que a prioritária associação entre pensamento e linguagem watsoniana denuncia influências indiretas da tradição filosófica grega clássica.
\end{abstract}

Palavras-chave: Watson; pensamento; behaviorismo; história da Psicologia.

\section{The Thinking in Watson: Breaking with the Metaphysical Legacy and Searching for a Materializing Reference}

\begin{abstract}
The work of Watson about thinking was treated inadequately by many interpreters, generating a gap in the history of Psychology, since Watson exerted ample influence on Psychology. Our objective is to elucidate part of this problem by clarifying the main Watson's positions about the thought. Our hypothesis is that the Watson's theory about thinking as a habit is a form of materializing reference, influenced by the demetaphysization of the Western thought originating from the Iluminism. We admit that his theory reproduced premises of the Cartesian error of category. We also assume that the prioritary association between thinking and language in Watson denounces indirect influences of the classic greek philosophical tradition.
\end{abstract}

Key words: Watson; thinking; behaviorism; history of Psychology.

O artigo de John Broadus Watson (1878-1958) Psychology as the Behaviorist Views it (1913) é frequentemente citado como apresentação da plataforma do seu behaviorismo (Chiesa, 1994). Apesar do impacto histórico inquestionável sobre a psicologia, Carrara (2005) salienta que o extenso trabalho de Watson tem sido muitas vezes tratado de forma superficial por muitos dos intérpretes de seu pensamento. Essa negligência interpretativa aparece especialmente quanto ao que Watson escreveu sobre o pensamento. Um exemplo aparece em Gardner (1985/2003), que afirmou que o tema do pensamento foi abafado pelo behaviorismo. Dorsch, Häcker e Stapf (1987/2001) afirmam que Watson propôs que as teorias psicológicas "deveriam evitar conteúdos que só se dão por introspecção (pensamento, sentimento, percepção)" (p. 109, o grifo é meu). Oliveira (1992) afirmou que o advento do behaviorismo significou um enfoque apenas dos "fenômenos externos" (p. 55). São comuns também afirmações superficiais, feitas sem um exame sistemático acerca do que Watson escreveu sobre pensamento, que pouco esclarecem. Este é o caso de Sternberg (2000): "Watson, que desconsiderava os conteúdos e os mecanismos mentais internos, menosprezou o

1 Endereço: Rua 24, nº 245, Ed. Miguel Jorge, Apto. 604, Setor Central, Goiânia, GO, Brasil 74030-060.E-mail: claudioivan.psi@ucg.br pensamento como uma fala sub-vocal" (p. 29, o grifo é meu). No mesmo caso se enquadram Seidl de Moura e Correa (1997), que, citando apenas Watson (1913), afirmam que Watson é conhecido por suas concepções “(...) um tanto simplistas sobre o pensamento" (p. 59). A negligência e interpretação questionável acerca do que Watson escreveu sobre pensamento não se restringem aos trabalhos de autores não behavioristas, como é o caso das citações acima. Baum (1999), um autor behaviorista, ao falar, no primeiro capítulo, do papel histórico de Watson na origem do behaviorismo cita apenas o artigo de Watson de 1913, texto que não revela as posições teóricas que Watson desenvolveu quanto ao tema do pensamento. Ao tratar do tema do pensamento no capítulo oito, Baum (1999) não analisa as posições de Watson que, como sustentaram Marx e Hillix (1963/2001) e Oliveira (2004), foram importantes como influências a partes da teoria de Skinner (1957).

Como veremos na exposição sobre as posições teóricas de Watson $(1920,1924 / 1970)$ acerca do pensamento, todas as afirmações feitas pelos intérpretes de sua teoria citados acima parecem menos absolutas, já que Watson (1920, 1924/1970) usou o conceito de pensamento, atribuindo ampla importância a este fenômeno na teorização sobre o comportamento, bem como admitiu uma forma de auto-observação e aceitou o pensamento como comportamento inferido (Watson, 1920).

Nosso objetivo é suprir uma lacuna no exame histórico da Psicologia, esclarecendo que Watson desenvolveu teorizações 
sobre pensamento pouco conhecidas e mal compreendidas em grande parte da literatura que interpreta seu papel histórico na Psicologia. Pretendemos esclarecer também que Watson admitiu a auto-observação dentro de limites apresentados em sua teoria.

Nossa hipótese é que a teoria de Watson sobre o pensamento como hábito é uma forma de referencialização materializante. Por referencialização materializante compreendemos o postulado de que os conceitos psicológicos precisam ser objetivados enquanto referenciados a ocorrências no corpo, no sentido de que cada conceito psicológico indica ocorrências materiais especificáveis. Admitimos também que este postulado de referencialização materializante foi alimentado pelo processo de desmetafisicização do mundo operado sobretudo a partir do pensamento Iluminista, destacadamente por Kant (1781/1971), que considerou a especulação metafísica vazia e infrutífera. A proposta de desmetafisicização de Kant teve um desdobramento radical no positivismo de Auguste Comte, em sua proposta de abandono da metafísica no pensamento científico materialista. A desmetafisicização do mundo, levada adiante pela evolução da ciência empíricoformal desembocou, para muitos de seus intérpretes, dentre eles Watson, no pressuposto de que o ser habita o concreto. Sendo assim, para Watson os conceitos psicológicos só possuem realidade se apresentarem um referente empírico demonstrável, presente nas ocorrências fisiológicas. A postura de Watson representa a aplicação radical da referencialização materializante à Psicologia em luta contra a metafísica dos conceitos psicológicos apresentada em Descartes (Heidbreder, 1933/1981) e prenunciada na tradição grega platônica.

Outra hipótese de nosso trabalho é de que a referencialização materializante de Watson acabou por assumir o erro de categoria cartesiano (Ryle, 1949). Tanto para o dualismo cartesiano quanto para a referencialização materializante de Watson, os conceitos psicológicos, no caso tratando-se do pensamento e das emoções, referem-se a uma ocorrência em algum lugar. Para Descartes, o palco dessas ocorrências é a substância pensante, para Watson são os movimentos musculares nos hábitos manipulativos ou nos movimentos viscerais (emoções). O erro de categoria apresenta uma ontologia dos conceitos mentais na qual eles estão em algum lugar, seja ele material ou imaterial (Ryle, 1949). Sustentamos também que a prioritária associação entre pensamento e linguagem em Watson denuncia influência indireta de tradições filosóficas gregas enraizadas em Parmênides de Eléia.

\section{O tratamento do pensamento em Watson}

Watson (1913), em sua busca por uma psicologia objetiva, teceu fortes críticas ao uso da introspecção:

\footnotetext{
Ela (a psicologia) tem falhado significativamente, eu acredito, durante os cinqüenta e poucos anos de sua existência, como uma ciência experimental para tomar seu lugar no mundo como uma indiscutível ciência experimental. A Psicologia, como ela é geralmente concebida, tem alguma coisa de esotérico em seus métodos. Se você falha em reproduzir minhas descobertas, isto não é por alguma falha em seu aparato ou no controle de seus estímulos, mas é devido ao fato de que sua introspecção não é treinada. O ataque é dirigido ao observador, não às
}

condições experimentais. Em física e química o ataque se dirige às condições experimentais. $O$ aparato não é sensível o suficiente, produtos químicos impuros estão sendo usados, etc. Nestas ciências, uma técnica melhor levará a resultados reproduzíveis. Na psicologia é de outra forma, se você não pode observar três a nove estados de clareza na atenção, sua introspecção é pobre. (pp. 4-3).

Fica claro o interesse de Watson (1913) por uma ciência experimental, objetiva, próxima às ciências naturais, na qual não poderia ser tolerada a subjetividade do método introspectivo (Heidbreder, 1933/1981; Schultz \& Schultz, 1967/1992).

Watson $(1924 / 1970,1920)$ é um autor que se preocupou com o conceito de pensamento. Ele ficou conhecido por sua definição do objeto de estudo da psicologia como sendo observável, o comportamento (Watson, 1924/1970). Com o conceito de comportamento, Watson (1924/1970) estava incluindo o pensamento e a linguagem (Nalini \& Oliveira-Castro, 2003; Watson, 1928/1980). O seguinte trecho ilustra tais posições:

O behaviorista pergunta: Por que nós não podemos fazer do que realmente observamos, o campo real da psicologia? Vamos nos limitar a coisas que podemos observar, e formular leis concernentes a somente tais coisas. Agora, o que nós podemos observar? Nós podemos observar o comportamento-o que os organismos fazem ou dizem. E deixe-me pontuar isso novamente: que dizer é fazer - isto é, comportar-se. Falar audivelmente ou para si mesmo (pensar) é exatamente um tipo de comportamento tão objetivo quanto jogar beisebol. (Watson, 1924/1970, p. 7; o grifo é do autor).

Esta afirmação de Watson significa dizer que pensamento é hábito, isto é, um grupamento organizado de respostas bem estabelecidas a partir de situações de condicionamento. Jogar tênis, praticar esgrima e as práticas religiosas são hábitos. Todos os hábitos envolvem um amplo conjunto de reações viscerais e musculares que ocorrem no corpo. No caso do pensamento, Watson (1924/1970) entendia que quando uma pessoa pensa, ela pode executar hábitos manipulativos lingüísticos, como pequenos movimentos na laringe, ao falar consigo mesmo inaudivelmente. Pode também executar movimentos nos dedos, ao fazer cálculos aritméticos, bem como contrair a musculatura da face. A pessoa pensa com o corpo como um todo. Caso as mãos estejam ocupadas, outras reações podem ser realizadas em outras partes do corpo. Watson $(1920,1924 / 1970)$ esclareceu que não considerava o pensamento como vinculado exclusivamente aos hábitos manipulativos da laringe. Ele entendia que havia uma plasticidade do pensamento, no que concerne a suas alternativas de realização em hábitos no corpo:

Um homem adulto pensa com o corpo todo em cada uma e em todas as partes. Se ele for mutilado, ou se seus órgãos são defeituosos ou estão faltando, ele pensa com as partes restantes deixadas em seu poder: mas seguramente, ele faz, tudo mais exatamente da mesma maneira. Se alguém estuda um jogo de tênis, sua observação é direcionada para o tipo de golpe que 
o jogador faz, seu serviço, seus retornos, a maneira como ele cobre a quadra, etc. Em outras palavras, a atividade de braços e pernas é enfatizada. Entretanto, qualquer um admite que o jogador está usando todas as células do seu corpo durante o jogo (...). Esta ilustração serve-nos muito bem para explicar porque alguém enfatiza processos da laringe no pensamento. Seguramente nós sabemos que surdos e mudos não usam estes processos da laringe, nem ofazem indivíduos cuja laringe foi removida. Outro processo corporal tem que tomar a função da laringe. Estas funções são usualmente usurpadas por dedos, mãos, braços, músculos faciais, músculos da cabeça, etc. (Watson, 1920, p. 2).

Watson (1924/1970) salientou que há três formas de organização que se desenvolvem juntas e interdependentemente em quase todas as atividades. Trata-se da organização verbal (depois que ela se inicia), da organização manual, e da organização visceral (relacionada às emoções). Em suma, nossas mãos, laringe e vísceras aprendem juntas e funcionam juntas. No entanto, a tendência é que a organização verbal ganhe proeminência, tornando-se um sistema de primeira ordem, enquanto a organização manual e visceral são sistemas de segunda ordem. Watson (1924/1970) explicita a questão:

Nós reagimos verbalmente, aberta ou encobertamente primeiro a quase todas as situações (a assim chamada "dominância da reação verbal”) - e então seguem-se as reações manuais e viscerais em ordem e na extensão na qual foram condicionadas. Em outras palavras nós, como adultos sofisticados, comportamo-nos como se condicionamento verbal fosse de primeira ordem, e o manual e o visceral de ordem secundária. (p. 254; o grifo é do autor).

Watson (1924/1970) afirmou que a organização verbal age para iniciar parte da organização total quando realizamos atividades como jogar golfe. Isso ocorre devido à idéia de que depois da formação de um hábito, as respostas verbais, musculares ou viscerais podem tornar-se substitutos para estímulos. Um exemplo é o caso de um músico habilidoso, que só precisa da primeira nota para executar todo $\mathrm{o}$ processo. As respostas que se seguem à primeira nota, verbais, manuais ou viscerais, agem como substitutas para a segunda nota. Essas respostas influenciam-se mutuamente. Na maioria dos casos, porém, há uma dominância da organização verbal sobre a manual e a visceral.

Watson (1924/1970) afirmou existirem hábitos para os quais organizações verbais não participam. É o caso dos hábitos desenvolvidos antes da formação das habilidades verbais, na infância. Além disso, mesmo na vida adulta há muitas reações viscerais para as quais não há demandas sociais que exijam o desenvolvimento de hábitos verbais a elas relacionados, é o caso de muitos aspectos da atividade sexual. No entanto, a regra para Watson, no caso do homem desenvolvido, é a primazia da organização verbal, na qual a palavra-estímulo pode iniciar um processo organizado ou mudar um processo em andamento.

Watson (1924/1970) indagou sobre a possibilidade de pensamento sem palavra. O seguinte trecho esclarece sua posição a esse respeito:
Em outras palavras, a partir do momento em que um problema é apresentado para o indivíduo (pela situação na qual ele está) a atividade que pode levar ao ajustamento entra em andamento. Algumas vezes a atividade caminha em termos de (1) organização manual; mais freqüentemente em termos de (2) organização verbal implícita; algumas vezes em termos de (3) organização visceral implícita (ou aberta). Se (1) ou (2) dominam, o pensamento ocorre sem palavras. (Watson, 1924/1970, pp. 266-267; o grifo é do autor).

Assim, fica claro que o pensamento, para Watson, pode ocorrer sem palavras. Quando um sistema é bloqueado, o outro entra em ação. No entanto, a predominância final do sistema verbal no processo de ajustamento é afirmada, pois a resposta final de ajustamento, se alguma é atingida, deve ser verbal (sub-vocal) (Watson, 1924/1970).

Sem negar a plasticidade dos hábitos de pensamento por todo o corpo, Watson $(1920,1924 / 1970)$ reconheceu que os hábitos manipulativos da laringe possuem papel privilegiado no pensamento. Em primeiro lugar, por uma razão estrutural. As estruturas da laringe são especialmente privilegiadas para a formação de hábitos de pensamento. Outra razão é biológico-evolutiva, no sentido de que as mãos, no caso da espécie humana, devem permanecer livres para executar trabalho e defesa. Pensamento e movimento das mãos, especialmente nas situações que exigem ambos, devem ocorrer em estruturas separadas.

Um ponto a ser salientado na teoria de Watson (1920) sobre a relação entre pensamento e linguagem é que pensamento não se restringe a situações de resolução de problemas. A atividade implícita, sub-vocal, com linguagem, é suficiente para caracterizar pensamento. Watson (1920) considera que a recitação sub-vocal de uma poesia, ou a divagação (day dreaming), é pensamento tanto quanto solucionar um problema aritmético. Apesar disso, ele considerou necessário, quanto aos interesses da psicologia, dividir em três níveis aquilo que chamou pensamento. Estes níveis variam quanto ao grau de prontidão e estereotipia do comportamento. No primeiro nível estão os hábitos vocais mais estereotipados, tais como citar um versículo bíblico decorado, ou muitas respostas em matemática, como "dois mais dois é igual a quatro". Watson (1920) colocou nesse primeiro nível a divagação, que ocorre como resposta à ausência de estímulos (sexo, alimento, água, drogas), ou seu uso (drogas).

No segundo nível estão as situações menos estereotipadas, nas quais se lida com resolução de problemas que não são novos, que não se tornaram padronizados, mas já são medianamente conhecidos. Watson (1920) usa como exemplo o caso em que alguém aplica uma fórmula matemática bem conhecida a um problema particular, ainda não solucionado pela pessoa. No terceiro nível estão as situações-problema realmente novas, para as quais o organismo não apresenta uma resposta estabelecida. É assumido que o tipo de resposta necessária para atingir a solução do problema é verbal: "O problema, é assumido, é de tal caráter que deve ser trabalhado verbalmente antes que qualquer ação pública tome lugar" (Watson, 1920, p. $3)$. Problemas sociais e morais, nos quais se deve refletir antes de tomar decisões, são de tal natureza. 
Quanto à relação entre pensamento e emoção, o fato de que o pensamento é uma atividade que envolve o corpo todo implica que os estados biológicos e emocionais o influenciam. As emoções se relacionam a reações nas glândulas viscerais, e elas estão em operação no corpo quando o organismo pensa. Watson (1924/1970) cita exemplos que hoje seriam classificados como fobia social.

Quanto ao aspecto metodológico, Watson (1920) admitiu que o pensamento pode ser estudado pedindo-se para o sujeito pensar em voz alta, visto que a natureza do processo de pensar em voz alta diante de uma situação-problema não seria essencialmente diferente de quando se faz isso inaudivelmente. Assim, o behaviorista poderia admitir a existência do pensamento com base em "uma inferência lógica." (Watson, 1920, p. 5; o grifo é meu):

\begin{abstract}
Naqueles casos nos quais a resposta ao estímulo não é imediata, mas finalmente ocorre em alguma forma de comportamento verbal ou manual explícito, é correto dizer que alguma coisa estava em andamento, e que aquela coisa é seguramente não diferente em essência daquela que ocorre quando o comportamento é explícito.
\end{abstract}

Esta citação mostra que Watson (1920, 1924/1970) não negou a validade de inferir o processo de pensamento nãoaudível, a partir do processo audível. Watson (1920) salientou que sua aceitação da inferência acerca de eventos implícitos não implicou aderir ao método introspectivo da psicologia estrutural de Titchener (1898), afirmando que o sujeito pode observar que está usando palavras em seu pensamento, mas não pode observar quanto material verbal é utilizado, nem o quanto sua formulação final é influenciada por fatores implícitos que não são postos em palavras e não podem ser observados por ele mesmo. Em suma, a introspecção não é suficiente porque muito do que é importante para compreender o pensamento não é acessível à auto-observação do sujeito. Para conhecer mais do que a análise do pensar alto permite, seria necessário usar instrumentos (Watson, 1920), especialmente de instrumentos fisiológicos que permitam medir os hábitos de pensamento. Podemos concluir que Watson rejeitou as pretensões do método introspectivo de Titchener, mas não rejeitou a validade da auto-observação dentro dos critérios propostos acima. Esta retificação é importante, pois corrige a interpretação corrente de que Watson rejeitou toda forma de auto-observação na psicologia (e.g., Doron \& Parot, 2002; Sillamy, 1996/1998). Na verdade, muitas das práticas hodiernas na psicologia, denominadas de introspecção, aproximam-se muito do que Watson chamou de auto-observação e seriam aceitas como válidas em sua teoria. É prática comum na literatura atual tratar o conceito de introspecção como sinônimo de auto-observação do pensamento e dos estados emocionais (e.g., Dorsch, \& cols., 1987/2001; Sternberg, 2000), possibilidade que não foi negada por Watson. O uso de introspecção como autorelato em situações de resolução de problemas, presente em estudos cognitivistas (Nisbett \& Wilson, 1977; Williams, Watts, Macleod \& Mathews, 1997/2000) e behavioristas radicais (e.g., Oliveira, Oliveira-Castro, Simonassi \& Vieira, 2002) não seria contestado por Watson, ao contrário do que interpretaram Sillamy (1998) e Doron e Parot (2002).
Também é comum hoje admitir os limites para a capacidade introspectiva de auto-observação de sujeitos experimentais (Maier, 1931; Nisbett \& Wilson, 1977), ponto que concorda com as críticas de Watson. Em suma, muito do que hoje é chamado de introspecção na psicologia, seria aceito como auto-observação por Watson.

Com base nas considerações feitas acima, propomos que a polêmica de Watson contra o método introspectivo seja contextualizada, isto é, ela representa um combate a uma forma epistemológica específica de compreensão da introspecção, vinculada especialmente à proposta de Titchener (muito menos que Wundt). Watson rejeitou as pretensões e postulados implícitos ao método introspectivo da Psicologia estrutural (Titchener, 1898), mas não rejeitou a validade da auto-observação. Uma das razões da crítica de Watson ao método introspectivo de Titchener refere-se à limitação lingüística do sujeito para descrever vários de seus comportamentos. Como vimos acima, Watson afirmou que o indivíduo não desenvolve linguagem adequada para descrever vários de seus comportamentos viscerais, ou aqueles desenvolvidos durante a infância antes da aquisição de um repertório verbal apropriado à descrição. Assim sendo, a auto-observação (introspecção) apresenta limites quanto a sua possibilidade reveladora. Watson não achava factível a proposta de Titchener, de que se poderia treinar os sujeitos para desenvolver uma linguagem adequada para descrever vivências subjetivas para as quais a sociedade não apresentou demanda descritiva. Historicamente, o otimismo epistemológico de Titchener (1898) quanto à introspecção foi influenciado pela premissa cartesiana de que o que é psicológico é consciente, assim sendo, a vivência psicológica torna-se evidente para o sujeito no palco de sua consciência, sendo acessível a sua introspecção (Ryle, 1949). Portanto, é de se compreender o otimismo vivido por grande parte da psicologia em relação às possibilidades da introspecção como uma via suficiente e fidedigna para o estudo do objeto da psicologia, a consciência.

Tal contextualização da polêmica de Watson contra o método introspectivo permite esclarecer que muitos dos usos contemporâneos de introspecção não assumem as pretensões epistemológicas de Titchener, e seriam admitidas como auto-observação por Watson. Assim sendo, é incorreto afirmar que Watson rejeitou, a priori, a auto-observação. Além disso, as críticas recentes impondo limites à introspecção (Nisbett \& Wilson, 1977) romperam com o postulado cartesiano de que a introspecção é suficiente para conhecer o fenômeno psicológico.

Quanto à origem ontogenética do pensamento, Watson (1924/1970) propôs que primeiro os hábitos de fala em voz alta são desenvolvidos, depois surge a fala sub-vocal, denominada de pensamento por Watson $(1920,1924 / 1970)$. O processo de redução de movimentos visíveis na fala, até o surgimento da fala sub-vocal, é descrito por Watson (1924/1970). Segundo ele, as crianças falam em voz alta, mesmo quando sozinhas. Os adultos exercem pressões sociais para que as crianças não falem em voz alta o tempo todo. O primeiro passo na redução gradual é o sussurro, observado nos movimentos labiais das crianças durante a leitura silenciosa. A pressão social punitiva alimenta o processo de desaparecimento do sussurro, ao apresentar repreensões do tipo: "você não pode ler sem mover seus lábios?". 
A organização lingüística, cuja fala sub-vocal é uma parte, assume, ao longo do desenvolvimento, a preponderância em relação aos repertórios visceral (emoção) e manual. Isto ocorre porque a maioria dos ajustamentos exigidos pelas demandas do ambiente, à medida que o indivíduo se insere em seu grupo, tende a ser verbal (Nalini \& Oliveira-Castro, 2003). Esta tese se relaciona à noção de que as palavras, à medida que apresentam função de substituir os objetos e situações, passam a evocar as respostas antes evocadas pelos objetos. Assim, a emissão de uma palavra, sub-vocalmente ou não, apresenta a função de controlar e evocar uma resposta motora. Isso não nega que Watson considerou que muitas vezes os hábitos emocionais viscerais podem tomar proeminência sobre o controle exercido pelos hábitos de pensamento, como é o caso de um aluno que não consegue responder a uma pergunta devido ao domínio de hábitos viscerais (ansiedade) diante de um professor que esbraveja.

Um fato importante na teoria de Watson é percebido quando ele tenta analisar a questão: quando nós pensamos? A resposta de Watson (1924/1970) aponta, pelo menos parcialmente, para situações em que tentamos nos esquivar de constrangimento social, ou conseqüências desagradáveis em geral.

As considerações acima mostram que o pensamento foi uma preocupação marcante na teoria de Watson, ao atribuir ao pensamento importância na ativação ou mediatização do comportamento manifesto, especialmente em situações para as quais o indivíduo não possui respostas prontas, incluindo situações sociais. Fica claro que longe está de ser verdade que Watson menosprezou ou negou a importância do pensamento.

\section{A tentativa de objetivar o objeto da psicologia: a referencialização materializante}

Para compreender as razões da tentativa de Watson para fisiologizar o pensamento, devemos compreender o contexto histórico da psicologia quanto à tensão entre a objetividade $\mathrm{e}$ a subjetividade (Vygotsky, 1926/1999). O conceito de mente estava relacionado a uma forte tradição dualista cartesiana, na qual a mente era compreendida como uma substância pensante (res cogitas), distinta do corpo como substância extensa (res extensa), muito embora Descartes (1637/1996) tenha deixado claro que corpo e mente são uma mistura. A solução anti-cartesiana, para muitos proponentes da psicologia científica nascente, foi produzir uma referencialidade material para os conceitos mentais, segundo os postulados de um materialismo emergente (Schultz \& Schultz, 1992; Vygotsky, 1982/1999). Como observou Francis Schaeffer (1967/1974), a filosofia da ciência moderna assumiu, em determinado momento de seu desenvolvimento, o postulado de um sistema fechado de causa e feito, em um franco projeto de desmetafisicização do mundo. Wertheirmer (1978) identificou o materialismo científico do século XIX como a tentativa de descrever os organismos vivos e seus processos estritamente como máquinas, em termos de fatos físicos e químicos, em franco ataque a toda forma de vitalismo (Mondin, 1977/1980). Na psicologia científica nascente no século XIX, este materialismo estimulou a tentativa de redução dos conceitos mentais a referentes físicos, sobretudo fisiológicos.
O postulado básico deste materialismo foi de que a forma de combater o dualismo cartesiano era identificar um plano material no qual o psicológico fosse referenciado, ideal que apareceu na premissa watsoniana apresentada por Marx e Hillix (2001), de que o comportamento compõe-se inteiramente de secreções glandulares e movimentos musculares; portanto, é basicamente redutível aos processos físico-químicos. Podemos chamar este postulado de referencialização materializante.

Pavlov (1926/1984, 1926/1984, 1990) seguiu rigorosamente a orientação do postulado da referencialização materializante, propondo que a fisiologia poderia estudar a atividade normal do córtice e da região sub-cortical vizinha, que seriam os aparelhos de relações entre o organismo e o meio circundante. Watson, apesar de não colocar sua ênfase no cérebro, como fizera Pavlov, seguiu a orientação do postulado da referencialização materializante dos conceitos psicológicos como defesa contra a tradição dualista cartesiana:

Um exemplo desse conceito religioso é que todo indivíduo possui uma alma que é separada e distinta do corpo. (...). Esta antiga visão leva à plataforma filosófica chamada "dualismo". Este dogma tem estado presente na psicologia deste a antiguidade. Ninguém jamais tocou uma alma, ou viu uma em um tubo de ensaio, ou entrou em relação com ela como entra em relação com outros objetos da sua experiência diária. (Watson, 1924/1970, p. 3; o grifo é do autor).

Fica clara uma tendência verificacionista (Carnap, 1936/1975) nos critérios que Watson adotou para deslegitimar o dualismo (tocar, tubo de ensaio). A referencialização materializante foi adotado por Watson (1920, 1924/1970), ao afirmar que o pensamento é um hábito, que se realiza na atividade fisiológica. Washburn (1922) identificou o que chamamos de postulado da referencialização materializante em Watson, visto que este afirmou que seu behaviorismo assumiu a tese de que o mundo da ciência física é um sistema fechado, no qual nada de externo às realidades físicas opera. Para enquadrar a psicologia dentro deste pressuposto, o behaviorismo de Watson teve que assumir que estímulos e respostas são movimentos, e devem ser descritos a partir dos mesmos conceitos físicos. Para Washburn (1922), essa é a origem da tese watsoniana de que pensamento é prioritariamente fala sub-vocal.

De acordo com nossa hipótese apresentada na introdução, o postulado da referencialização materializante foi alimentado pela desmetafisicização do mundo operada, sobretudo, a partir do pensamento Iluminista, destacadamente por Kant (1781/1971). Cabe lembrar que o Iluminismo apresentou uma crítica às possibilidades da razão. De acordo com Kant (1781/1971), em sua crítica à especulação metafísica teológica, não se pode alcançar qualquer conhecimento intelectual demonstrável e apodíctico acerca do supra-sensível. Foi, sobretudo, para a razão instrumental, aclamada modelarmente na razão técnico-científica da modernidade (Boff, 1998), que o Iluminismo abriu as portas. A filosofia da ciência em seu desenvolvimento pós-iluminista desdobrou as teses da desmetafisicização do mundo no positivismo de Comte. O desdobramento mais radical da desmetafisicização do mundo ocorreu no verificacionismo (Carnap, 1936/1975), em uma 
tendência de atribuir validade somente aos enunciados empíricos, destituindo de valor epistemologias que lidam com enunciados metaempíricos, como a teologia (Boff, 1998). A psicologia científica nascente no final do século XIX e início do século $\mathrm{XX}$, antes mesmo de Watson, teve que lidar com a luta anti-metafísica em sua linguagem (e.g., Vygotsky, 1982/1999). A postura de Watson, no sentido de encontrar um referente empírico para os conceitos psicológicos, desenvolveu a forma radical de um materialismo reducionista, expresso no postulado de que o ser habita o concreto, e de que todo conceito que se pretende revestir de realidade tem que referir-se a uma realidade pontual identificável no mundo empírico, como a atividade dos grandes hemisférios cerebrais (Pavlov) ou os movimentos musculares e viscerais (Watson). Destarte, Watson e Pavlov representam um tratamento reducionista dos conceitos psicológicos. Esta postura reducionista de Watson muito se relaciona ao que Marx e Hillix (2001) chamaram de behariorismo metafísico, em sua postulação de inexistência da mente como meta-empírica. Tal postura foi além do aspecto metodológico do behaviorismo de Watson, que negava a utilidade científica dos conceitos metafísicos, sem negar sua existência (Marx \& Hillix, 2001).

Em nosso entender, o reducionismo presente na referencialização materializante de Watson, ao combater o dualismo cartesiano, teve que fazê-lo em uma lógica de tratamento dos conceitos psicológicos idêntica à de Descartes. Para ambos (Descartes e Watson), o conceito de pensamento foi referenciado a uma ocorrência, seja no plano supra-sensível da substância pensante, ou no plano dos hábitos manipulativos da laringe e do corpo como um todo (Watson, 1920). Trabalhando com a interpretação do filósofo Gilbert Ryle (1949) sobre o mito de Descartes, podemos concluir que a referencialização materializante de Watson herdou do cartesianismo o chamado erro de categoria, que consiste em usar um conceito fora da geografia conceitual que se aplica a ele na linguagem cotidiana. No que tange ao conceito de pensamento, Ryle (1979) afirmou que este, em sua lógica cotidiana, possui um uso adverbial, isto é, trata do modo como fazemos alguma coisa. Assim sendo, podemos, por exemplo, ler um texto pensando, reflexivamente, ou podemos lê-lo mecanicamente, irreflexivamente. Neste contexto, pondera Ryle (1979), o conceito de pensar não trata de algo além do que fazemos quando lemos, mas do modo como realizamos a leitura. Destarte, não faz sentido perguntar onde ocorre o pensamento, dado não ser ele uma ocorrência que pode ser encontrada em um plano imaterial (Descartes) ou em um plano material (Watson). Independentemente de concordarmos ou não com as considerações de Ryle (1949), o ponto importante para nosso artigo é que a negação do dualismo cartesiano na psicologia watsoniana, presente na referencialização materializante, acabou por manifestar-se como uma incorporação de parte dos postulados referencialistas cartesianos.

Cabe salientar que o referencialismo cartesiano possui raízes muito antigas no pensamento Ocidental, remontando à tradição clássica grega e partes da tradição medieval. Dentre os gregos, um dos pontos iniciais da tradição referencialista remonta a Parmênides e Platão (Ryle, 1979). No poema $D a$ Natureza, Parmênides (séc V a. C./2000.) se propôs a investigar o caminho para o sólido saber. O termo caminho é uma

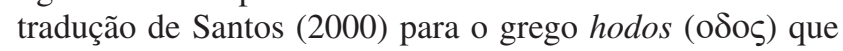

aparece em B2,2 (Parmênides, séc V a. C./ 2000). Segundo Santos (2000) este termo (hodos) indica uma pergunta sobre um método de investigação para chegar à verdade. Qual é o caminho para a identificação da verdade para Parmênides? Este caminho passa pela identificação entre ser e pensar. O ser identifica-se com o pensar "pois o mesmo é o ser e o pensar" (B3). Parece que esta conclusão de Parmênides dependeu de sua visão do problema da irreferencialidade do pensamento. De acordo com esta teoria de referencialidade do pensamento, somente o ser pode ser pensado, isto é, pode ser referenciado. O não-ser não é referenciável, logo, não pode ser pensado. Santos (2000) caracteriza o problema levantado por Parmênides como um problema de irreferencialidade:

Podemos tecnicamente dizer "irreferencialidade". O termo negativo não "indica" nada, não refere nenhuma entidade que se possa designar. Daí resulta sua incognoscibilidade. E desta, sua exclusão como "pensamento". Desta, por sua vez, decorre a identificação do ser e do pensar (Santos, 2000, p. 82; o grifo é meu).

O corolário da teoria de Parmênides de Eléia, de que pensar e ser são idênticos, é que a linguagem deve ser entendida em sentido referencialista, para cada termo, há o seu respectivo ser. A filosofia de Platão, em sua afirmação gnosiológica de que o conhecimento presente na alma é proveniente da

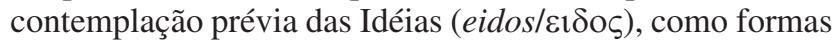
eternas imutáveis (Platão, 385 a. C./1987), foi muito influenciada pela posição de Parmênides. Assim, Platão construiu uma posição referencialista, na qual os conceitos pensados possuem um correspondente originário em uma essência supra-sensível (Reale, 1975/1993, 1994).

No medievo, Agostinho (383-395/1995) revisou a gnosiologia platônica à luz dos postulados cristãos, afirmando que as idéias presentes na alma do homem foram impressas por Deus e, para toda idéia presente na alma humana, há um exemplar (ver exemplarismo: Boehner \& Gilson, 1952/1988) que existe eternamente em Deus. Nesse sentido, Agostinho, ao revisar Platão, manteve a tese referencialista platônica, de que os conceitos pensados pelo homem possuem um referente transcendente, metaempírico.

Note-se aqui que o discurso presente no surgimento da psicologia científica moderna, marcadamente no behaviorismo de Watson (Watson \& Dougall, 1924/1970), foi de que esta realizou uma ruptura com a psicologia presente na reflexão filosófica e teológica metafísica precedente. Pressuposto a este discurso de ruptura absoluta está o dogma epistemológico da modernidade, de que um novo conhecimento só pode ser construído mediante a ruptura com a tradição pré-moderna, sobretudo a escolástica. Esta foi a postura cartesiana no Discurso do método (Descartes, 1637/1996). Tal idéia de uma ruptura absoluta levou a uma postura historiográfica sobremodo equivocada na psicologia, na qual a psicologia científica nascente foi interpretada como uma construção que não teve influências das tradições teológicas e filosóficas pré-modernas, dado que estas foram compreendidas como negação do moderno (Bauman, 1995/1999; Oliveira, 2004). Ao contrário disso, nossa discussão mostra que mesmo o empreendimento desmetafisicizante da linguagem psicológica, herdeiro do Iluminismo e assumido pelo 
behaviorismo de Watson, incorporou uma lógica ontológicoreferencialista construída na própria tradição filosófica e teológica que a psicologia desmetafisicizante queria negar. Historiograficamente, nossas considerações alertam-nos para o perigo de adotarmos acriticamente a interpretação de que a construção da psicologia científica foi uma absoluta negação da tradição presente na psicologia pré-científica. Uma postura historiográfica mais proveitosa é manter aberta a possibilidade de influências da tradição psicológica pré-científica sobre os sistemas da nova psicologia.

\section{A relação entre pensamento e linguagem em Watson}

A teoria de Watson, direcionada pelo postulado da referencialização materializante, reforçou a clássica tradição de associar pensamento e linguagem ao definir o pensamento prioritariamente, ainda que não exclusivamente, como fala sub-vocal. Essa tendência é evidenciada quando Watson (1924/1970), ao diferenciar três níveis de pensamento, colocou no primeiro nível, hábitos verbais estereotipados, como recitar um versículo bíblico ou divagar. Nesse ponto, Watson revisou o conceito de pensamento em relação a sua lógica cotidiana, na qual há claras situações de distinção entre dizer e pensar. Na linguagem cotidiana, os hábitos verbais estereotipados e a divagação não são conceitos identificados ao pensamento, assim, é possível dizer sem pensar (Ryle, 1979). Vale notar que a sobreposição entre pensamento e linguagem em Watson não é total, visto que ele admitiu que o pensamento pode ocorrer sem palavras, quando participam prioritariamente, conjuntamente ou não, os sistemas motor e visceral. No entanto, essa distinção não foi a prioridade da interpretação de Watson para o pensamento.

Cabe salientar que a tradição de identificação entre pensamento e linguagem possui raízes muito antigas no pensamento Ocidental, remontando à tradição clássica grega. Essa interpretação é adotada por Ryle (1979), que remonta a Platão, no diálogo Sofista, uma definição de pensamento que identifica pensamento e fala consigo mesmo: "no pensamento a alma está conversando consigo mesma" (Ryle, 1979, p. 33). Outro aspecto do pensamento grego que marcou uma forte associação entre pensamento e linguagem foi a discussão de Aristóteles (séc. IV a. C./2001) sobre as virtudes dianoéticas. Tal discussão aparece na análise de Aristóteles (séc. IV a. C./2001) sobre a psicologia do ato moral e foi retomada por Tomás de Aquino, um dos pensadores mais influentes do medievo (Mondin, 1977/1980). Sendo assim, a identificação entre pensamento e linguagem tem raízes em uma tradição muito anterior à formação da psicologia científica nascente. Nesse aspecto, portanto, o bahaviorismo de Watson, em sua ênfase na associação entre pensamento e linguagem, colocou-se em continuidade com uma longa tradição (Oliveira, 2004).

Cabe indagar, quanto ao contexto mais imediato a Watson, quais as razões para sua quase identificação entre pensamento e fala sub-vocal. Uma importante razão foi o impacto da teoria da evolução de Darwin sobre a psicologia. Com o pensamento de Darwin (1859/1985, 1872/2000), a idéia de uma continuidade evolucionária entre animal e humano colocou a necessidade de procurar elos comportamentais que ligassem o pensamento humano complexo a suas origens evolucionárias.
Umas das propostas para solucionar tal problema foi admitir que a mente humana complexa evoluiu a partir da mente animal menos complexa. Köhler (1925/1978, 1938/1980) e Vygotsky (1934/2001; Vygotsky \& Luria, 1930/1996) desempenharam amplo papel nessa busca. Köhler (1925/1978, 1938/1980) apresentou o conceito de inteligência prática dos antropóides, uma forma de resolução de problemas que trabalha sem linguagem. Para Vygotsky (1934/2001; Vygotsky \& Luria, 1930/1996), o pensamento prático dos antropóides foi entendido como um elo evolucionário de ligação entre o comportamento animal e o pensamento humano complexo, que trabalha com a linguagem. A solução proposta por Vygotsky para o problema da evolução dos comportamentos humanos complexos exigiu a aplicação do conceito de pensamento aos antropóides, bem como a separação entre pensamento e linguagem, quanto às formas mais primitivas de pensamento. Disso decorreu o afastamento e as críticas de Vygotsky (1934/2001) tanto em relação à postura teórica de Watson quanto à ênfase na vinculação entre pensamento e linguagem. Também sob o impacto da teoria de Darwin, William James (1890) extrapolou o conceito de inteligência e mentalidade para o contexto animal, não apenas humano, considerando estes conceitos relacionados a situações nas quais os animais são capazes de variar adaptativamente (inteligentemente) os meios mantendo constantes os propósitos. Nesse sentido, um animal apresenta comportamento inteligente ao usar o membro esquerdo quando o membro direito está obstruído quanto ao propósito de pegar alimento. Fica claro que, para James (1890), inteligência e linguagem são independentes, no aspecto referido acima.

Propostas sobre pensamento desvinculado de linguagem foram apresentadas pelos integrantes da Escola de Würzburg (Humphrey, 1973; Seidl de Moura \& Correa, 1997). Neste caso sem influência da teoria de Darwin.

As distinções de Watson, em relação a Vygotsky, Köhler e James, podem, em parte, ser atribuídas a posturas diferentes em relação ao problema evolucionário explicitado acima, imposto por Darwin. A postura de Vygotsky e Köhler foi de explicar o comportamento animal a partir de conceitos mentais cunhados tradicionalmente para o comportamento humano (pensamento, inteligência), enquanto Watson queria explicar o comportamento humano partindo de princípios construídos a partir da psicologia animal, rejeitando a adoção e aplicação de conceitos mentais que considerava obscuros. Esta postura de Watson foi influenciada por C. Lloyd Morgan (Marx \& Hillix, 2001), que propôs o princípio da parcimônia como critério para a interpretação do comportamento animal. Esta postura implicava em que sempre que uma explicação mais simples fosse possível para o comportamento animal, não se deveria recorrer a conceitos que evocassem comportamentos mais complexos, especialmente humanos. Com isso, Watson queria evitar a antropomorfização do comportamento animal. Antropomorfização que, como alertou Pavlov (1926/1984, 1926/1984), baseava-se em uma explicação dependente de inferências sobre ocorrências mentais nos animais e era influenciada pelo método introspectivo. Isto era incompatível com a estratégia explicativa de Watson. Também é claro que o behaviorismo de Watson não poderia trabalhar com o conceito de inteligência, muito menos com a definição deste conceito feita por James (1890), dado que James adotava a 
noção teleológica de propósito, inaceitável para o mecanicismo tautologicamente anti-teleológico de Watson.

Uma interessante diferença entre as teorias de Köhler e Vygotsky, em relação a Watson, é que em Watson, o conceito de pensamento, exatamente por ser aplicado prioritariamente aos casos de fala sub-vocal, foi considerado no contexto humano. Em Vygotsky e Köhler, o conceito de pensamento foi aplicado aos antropóides, saindo do contexto humano.

\section{Conclusões}

Nosso artigo argumentou que a preocupação de Watson com o pensamento foi fundamental em sua teoria. $\mathrm{Na}$ verdade, sem compreender a abordagem de Watson para o pensamento fica impossível compreender sua proposta para o comportamento humano. As discussões aqui apresentadas sobre as falhas nas interpretações acerca da teoria de Watson sustentam a proposição de que suas considerações (de Watson) sobre o pensamento são mais complexas e menos compreendidas do que ampla parte da literatura tem apresentado. Historicamente, faz-se necessário apresentar uma interpretação mais apropriada sobre este importante psicólogo, revelando que ele não rejeitou de modo absoluto a auto-observação. Argumentamos também que a teoria de Watson sobre pensamento só pode ser compreendida a partir de uma interpretação histórica que vá além do contexto imediato de nascimento da psicologia científica, deixando claras as raízes da referencialização materializante provenientes de um referencialismo cujas bases advêm do pensamento clássico grego.

Historiograficamente, o presente artigo denuncia a deficiência de uma abordagem histórica que assuma a priori que a psicologia científica, em sua construção de sistemas, é uma ruptura total com a psicologia presente em tradições filosóficas e teológicas que a antecederam. Estudos como Oliveira, Pires, Macedo e Siqueira (2006) e Penna (1998) têm apresentado evidências de influências do pensamento filosófico cartesiano e teológico paulino-agostiniano sobre teorias psicológicas contemporâneas. Tem faltado à história da psicologia uma investigação mais sistemática acerca das influências mais remotas sobre sua formação contemporânea.

\section{Referências}

Agostinho, Sto. (1995). O livre-arbítrio (N. A. Oliveira, Trad.). Em Patrística (Vol. 8). São Paulo: Paulus (Trabalho original publicado em 383-395)

Aristóteles (2001). Ética a Nicômacos (M. G. Kury, Trad.). Brasília: Editora Universidade de Brasília. (Trabalho original do séc. IV a. C.)

Baum, W. M. (1999). Compreender o Behaviorismo: ciência, comportamento e cultura (M. T. A. Silva, Trad.). Porto Alegre: Artes Médicas. (Trabalho original publicado em 1994)

Bauman, Z. (1999). Modernidade e ambivalência (M. Penchel, Trad.). Rio de Janeiro: Jorge Zahar. (Trabalho original publicado em 1995)

Boehner, P. \& Gilson, E. (1988). História da filosofia cristã: desde as origens até Nicolau de Cusa (R. Vier, Trad.). Petrópolis: Vozes. (Trabalho original publicado em 1952)
Boff, C. (1998). Teoria do método teológico. Petrópolis: Vozes. Carnap, R. (1975). Testabilidade e significado (P. R. Mariconda, Trad.). Em Os pensadores (pp. 177-219). São Paulo: Abril Cultural. (Trabalho original publicado em 1936)

Carrara, K. (2005). Behavorismo radical: crítica e metacrítica. São Paulo: Editora UNESP.

Chiesa, M. (1994). Radical behaviorism: The philosophy and the science. Boston: Autors Cooperative.

Darwin, C. (1985). A Origem das Espécies (E. Amado, Trad.). São Paulo: Itatiaia. (Trabalho original publicado em 1859)

Darwin, C. (2000). A Expressão das Emoções no Homem e nos Animais (L. S. L. Garcia, Trad.). São Paulo: Cia. Das Letras. (Trabalho original publicado em 1872)

Descartes, R. (1996). Discurso do método (M. E. Galvão, Trad.). São Paulo: Martins Fontes (Trabalho original publicado em 1637)

Doron, R. \& Parot, F. (2002). Dicionário de psicologia. São Paulo: Ática. (Trabalho original publicado em 1991)

Dorsch, F., Häcker, H. \& Stapf, K. H. (2001). Dicionário de psicologia Dorsch (E. C. Leão \& cols., Trad.). Petrópolis: Vozes. (Trabalho original publicado em 1987)

Gardner, H. (2003). A nova ciência da mente: uma história da revolução cognitiva (C. M. Caon, Trad.) São Paulo: EDUSP. (Trabalho original publicado em 1985)

Heidbreder, E. (1981). Psicologias do século XX (L. S. Blandy, Trad.). São Paulo: Mestre Jou. (Trabalho original publicado em 1933)

Humphrey, G. (1973). Psicologia del pensamiento (V. M. Alcaraz, Trad.). México: Trilhas.

James, W. (1890). The principles of psychology. Retirado em 22/10/05 de http://psychclassics.yorku.ca.

Kant, I. (1971). Crítica da razão pura. Rio de Janeiro: Edições de Ouro. (Trabalho original publicado em 1781)

Köhler, W. (1978). A Inteligência dos Antropóides (C. T. Massadar, Trad.). Em A. Engelmann. (Org.), Köhler (pp. 39-59). São Paulo: Ática. (Trabalho original publicado em 1925)

Köhler, W. (1980). Teoria relacional da aprendizagem (C. T. Massadar, Trad.). Em W. S. Sahakian (Org.), Aprendizagem: sistemas, modelos e teorias (pp. 294-299). Rio de Janeiro: Interamericana. (Trabalho original publicado em 1938)

Maier, N. R. F. (1931). Reasoning in humans: II. The solution of a problem and its appearance in consciousness. Journal of Comparative Psychology, 12, 181-194.

Marx, M. H. \& Hillix, W. A. (2001). Sistemas e teorias em psicologia (A. Cabral, Trad.). São Paulo: Cultrix. (Trabalho original publicado em 1963)

Mondin, B. (1980). O homem: quem é ele?: elementos de antropologia filosófica (R. L. Ferreira \& M. A. C. Ferrari, Trad.). São Paulo: Paulus. (Trabalho original publicado em 1977)

Nalini, L. E.G. \& Oliveira-Castro, J. M. (2003). Linguagem como comportamento nos behaviorismos watsoniano, radical e mediacional. Estudos, 30, 1107-1138.

Nisbett, R. E. \& Wilson, T. D. (1977). Telling more than we can know: verbal reports on mental processes. Psychological Review, 84, 231-259.

Oliveira, C. I. (2004). Análise histórica acerca do intelectualismo e de sua influência sobre teorias behavioristas, cognitivistas e sócio-histórica acerca do pensamento. Tese de Doutorado, Universidade de Brasília, Brasília. 
Oliveira, C. I., Oliveira-Castro, J. M., Simonassi, L. E. \& Vieira, T. M. (2002). Resolução de problemas e descrição de contingências: efeito da acurácia das instruções em tarefas sucessivas. Acta Comportamentalia. 10(1), 65-86.

Oliveira, C. I., Pires, A. C., Macedo, R. G. \& Siqueira, A. T. E. (2006). A antropologia paulino-agostiniana: a criação do paradigma da ambivalência do eu-moral e a interpretação do binômio saúde-doença. Memorandum, 10, 09-32. Retirado em 31/07/06 de http://www.fafich.ufmg.br/ memorandum/ a10/oliveira01.htm

Oliveira, M. K. (1992). O verbal e o não verbal. Revista USP, $16,52-61$.

Parmênides (2000). Da natureza (J. T. Santos, Trad.). Em J. T. Santos (Org.), Da natureza - Parmênides (pp. 16-31). São Paulo: Loyola (Trabalho original do séc. V a. C.)

Pavlov, I. P. (1984). O Trabalho dos Grandes Hemisférios Cerebrais (R. Moreno, Trad.). Em Os pensadores (pp. 85-98). São Paulo: Abril. (Trabalho original publicado em 1926)

Pavlov, I. P. (1984). A Natureza da Inteligência dos Macacos Antropóides e a Interpretação Errônea de Köhler (R. Moreno, Trad.). Em Os pensadores, (pp. 130-133). São Paulo: Abril. (Trabalho original publicado em 1934)

Pavlov, I. P. (1990). A propósito da possibilidade da fusão do subjetivo e do objetivo (J. Menezes, Trad.). Em Reflexos condicionados, inibição e outros textos (pp. 279-280). Petrópolis: Vozes. (Trabalho original publicado em 1933)

Penna, A. G. (1998). A presença do pensamento filosófico na psicologia contemporânea. Em J. Brozek \& M. Massini (Orgs.), Historiografia da psicologia moderna: versão brasileira (pp. 49-60). São Paulo: Loyola/Unimarco.

Platão (1987). Fédon (J. C. Souza, J. Paleikat \& J. C. Costa, Trad.). Em Os pensadores, v. 52 (pp. 57-126). São Paulo: Abril. (Trabalho original publicado em 385 a. C.)

Reale, G. (1993). História da Filosofia Antiga vol. 1 (M. Perine, Trad.). São Paulo: Loyola. (Trabalho original publicado em 1975)

Reale, G. (1994). História da Filosofia Antiga vol. 2 (H. C. L. Vaz \& M. Perine, Trad.). São Paulo: Loyola. (Trabalho original publicado em 1975)

Ryle, G. (1949). The concept of mind. London: Hutchinson \& Co.

Ryle, G. (1979). On thinking. Totowa: Rowman \& Littlefield.

Santos, J. T. (2000). Da natureza: Parmênides. Brasília: Thesaurus.

Schaeffer, F. A. (1974). A morte da razão (Tradutor não informado). São Paulo: ABU. (Trabalho original publicado em 1967)

Schultz, P. S. \& Schultz, S. L. (1992). História da psicologia moderna (A. U. Sobral \& M. S. Gonçalves, Trad.). São Paulo: Cultrix. (Trabalho original publicado em 1967)

Seidl de Moura, M. L. \& Correa, J. (1997). Estudo psicológico do pensamento: de Wundt a uma ciência da cognição. Rio de Janeiro: EdUERJ.
Sillamy, N. (1998). Dicionário de Psicologia Larousse (F. Frank, Trad.). Porto Alegre: Artes Médicas. (Trabalho original publicado em 1996)

Skinner, B. F. (1957). Verbal behavior. New York: AppletonCentury-Crofts, INC.

Sternberg, R. (2000). Psicologia cognitiva (M. R. B. Osório, Trad.). Porto Alegre: Artes Médicas.

Titchener, E. B. (1898). The postulates of a Structural Psychology. Retirado em 22/10/05 de http://psychclassics.yorku.ca

Vygotsky, L. S. (1999). Os métodos de investigação reflexológicos e psicológicos (C. Berliner, Trad.). Em Teoria e Método em Psicologia (pp. 3-31). São Paulo: Martins Fontes. (Trabalho original publicado em 1926)

Vygotsky, L. S. (2001). A Construção do Pensamento e da Linguagem (P. Bezerra, Trad.). São Paulo: Martins Fontes. (Trabalho original publicado em 1934)

Vygotsky, L. S. (1999). O Significado Histórico da Crise na Psicologia (C. Berliner, Trad.). Em Teoria e Método em Psicologia (pp. 203-423). São Paulo: Martins Fontes. (Trabalho original publicado em 1982)

Vygotsky, L. S. \& Luria, A. R. (1996). Estudos Sobre a História do Comportamento: Símios, Homem Primitivo e Criança (L. L. Oliveira, Trad.). São Paulo: Martins Fontes. (Trabalho original publicado em 1930)

Washburn, F. M. (1922). Introspection as an objective method. Retirado em 22/04/02 de http://psychclassics.yorku.ca

Watson, J. B. (1913). Psychology as the Behaviorist Views it. Retirado em 13/07/00 de http://psychclassics.yorku.ca

Watson, J. B. (1920). Is thinking merely the action of language mechanisms? Retirado em 22/04/02 de http://psychclassics. yorku.ca

Watson, J. B. (1970). Behaviorism. New York: Norton Library. (Trabalho original publicado em 1924)

Watson, J. B. (1980). Aprendizado verbal segundo o behaviorismo (C. T. Massadar, Trad.). Em W. S. Sahakian (Org.), Aprendizagem: sistemas, modelos e teorias (p. 21). Rio de Janeiro: Interamericana. (Trabalho original publicado em 1928)

Watson, J. B, \& MC Dougall, W. (1970). The Battle of Behaviorism. New York: Norton Library. (Trabalho original publicado em 1924)

Wertheimer, M. (1978). Pequena história da psicologia. São Paulo: Companhia Editora Nacional.

Williams, J. M. G., Watts, F. N., Macleod, C. \& Mathews, A. (2000). Psicologia cognitiva e perturbações emocionais (F. Anderson, Trad.). Lisboa: Climepsi editores. (Trabalho original publicado em 1997)

Recebido em 13.08.2006

Primeira decisão editorial em 07.11.2006

Versão final em 14.03.2007

Aceito em 19.11.2007 


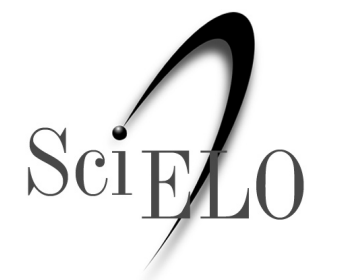

\section{A Revista Psicologia: Teoria e}

Pesquisa é publicada regularmente com

texto completo na Internet na Biblioteca

Científica Eletrônica Online - SciELO.

A SciELO permite o acesso fácil às tabelas de conteúdo e aos textos completos dos artigos.

A SciELO permite também a recuperação de artigos por autor, palavras do título, resumo e descritores, além de fornecer indicadores bibliométricos e de consultas.

Os textos são enriquecidos com conexões para as bases de dados LILACS e MEDLINE.

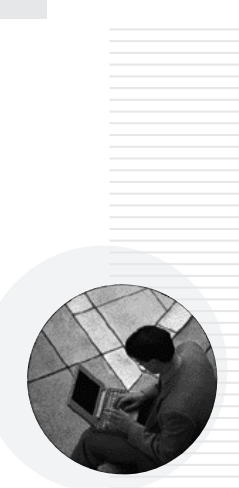

A Revista Psicologia: Teoria e Pesquisa é parte integrante da SciELO Brasil: www.scielo.br/ptp

0 Portal SciELO integra e promove acesso a rede de sites SciELO, reunindo as principais revistas científicas da América Latina e Espanha:

www.scielo.org

SciELO é fruto da cooperação entre a FAPESP, a BIREME e editores científicos. 